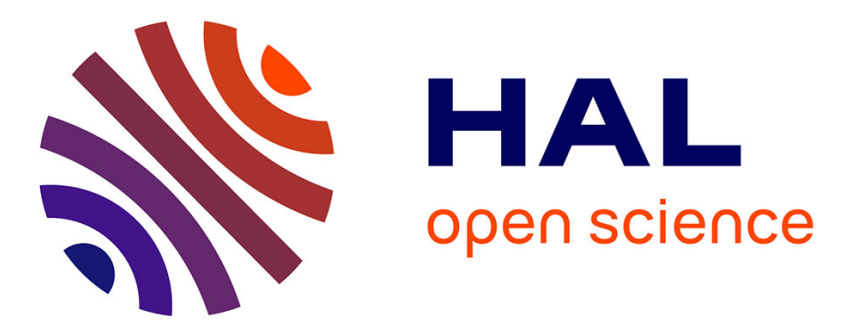

\title{
Knowledge Management on Asset Management for End of Life Products
}

\author{
N. Chakpitak, P. Loahavilai, K. Dahal, A. Bouras
}

\section{To cite this version:}

N. Chakpitak, P. Loahavilai, K. Dahal, A. Bouras. Knowledge Management on Asset Management for End of Life Products. 12th IFIP International Conference on Product Lifecycle Management (PLM), Oct 2015, Doha, Qatar. pp.428-443, 10.1007/978-3-319-33111-9_40 . hal-01377470

\author{
HAL Id: hal-01377470 \\ https://hal.inria.fr/hal-01377470
}

Submitted on 7 Oct 2016

HAL is a multi-disciplinary open access archive for the deposit and dissemination of scientific research documents, whether they are published or not. The documents may come from teaching and research institutions in France or abroad, or from public or private research centers.
L'archive ouverte pluridisciplinaire HAL, est destinée au dépôt et à la diffusion de documents scientifiques de niveau recherche, publiés ou non, émanant des établissements d'enseignement et de recherche français ou étrangers, des laboratoires publics ou privés. 


\title{
Knowledge Management on Asset Management for End of Life Products
}

\author{
N. Chakpitak ${ }^{1}$, P. Loahavilai' ${ }^{2}$ K. Dahal ${ }^{3}$, A. Bouras ${ }^{4}$ \\ ${ }^{1,2}$ International College, Chiang Mai University, Thailand \\ 'Nopasit@camt.info, ${ }^{2}$ piangor@ hotmail.com \\ ${ }^{3}$ University of the West of Scotland \\ Keshav.Dahal@uws.ac.uk \\ ${ }^{4}$ College of Engineering, Qatar University \\ abdelaziz.bouras@qu.edu.qa
}

\begin{abstract}
Because of considerable high labor cost in developed countries particularly Japan and Korea, the end of life products required manual or semimanual processes have been relocated to developing countries. In addition, the relocation creates an immediate financial profit on old asset sale while it is revalued to $30 \%$ of its initial value in the new relocated factory. The relocation is not only production location change but also the experience in operation and maintenance process to its Foreign Direct Investment affiliate. Since the old product and process are both nearly at their end of life, it needs to extend the life as long as the product still exists in the market. In order to immediately launch the operation as well as to retain the knowledge, therefore, the asset management and new maintenance modes are proposed at all product, process and people aspects to improve reliability of the old asset and to minimize maintenance cost. The research in this paper was carried out on a Korean relocated electronic factory in Thailand. The result clearly shows that the reliability, quality, cost and intellectual capital are significantly improved.
\end{abstract}

Keywords: Knowledge Management, Asset Management, Reliability Centered Maintenance, End-of-life Product, Factory Relocation

\section{Introduction}

There has been a significant rapid increase in Foreign Direct Investment (FDI) outflow to developing countries in Asian, Latin America since the late of 1980's.[1] Normally, FDI transfer tangible assets and intangible assets to the FDI overseas, where it provides some potential benefit.[2] For other reason, FDI may need to protect its cost competitiveness advantage through the transfer.[3] The FDI from East Asian countries also invest in developing countries in Asia. Most of Japanese FDI moves their production to a new location where the production costs were lower.[4] 
Anyhow, the Korean FDI invests aboard to utilize the lower labor cost and to reconstruct the less competitive domestic industries.[5]

At the early stage, the motive frequently is driven by the cost competitiveness. The old equipment, which is running beyond its engineering designed life, the life cycle cost of machine replacement shall be a significant financial burden. Because the life cycle cost includes not only the acquisition costs, but also the ownership costs and the disposal costs.[6] Moreover, it needs a considerable decision to invest in the production of the old 'sunset' product in the industry of high precision or high manufacturing technology.

It is not justified to invest on new machinery for the old products, which normally have no market growth or a declining market. Therefore, the retrofit of a company's equipment with the shift of the maintenance system for a longer profitable period is the most appropriate solution.[7] Even the old products cannot make a lot of profit, but the product owner company can keep the market as well as spare part service to customers. The product has no longer investment cost, and the production equipment is still available. Moreover, the production technology is nearly obsolete or requires unskilled labor. In the developed countries, the labor cost is much more expensive.

This research uses a case study of a FDI who loses their cost competitiveness in an old location in a developed country. The FDI chooses to relocate the old machinery to the cheaper operation cost location in a developing country.

\section{Literature Review}

In this relocation scenario, new technology should be employed in order to save the cost of unskilled labor. Therefore, the old technology production line has to be replaced by a new one, and then, relocate the old one to developing countries. The knowledge in operation and maintenance for the equipment should be transferred from the old plant in the developed country to a new factory in developing country. [8] Finally the new plant tries to keep running the production as long as possible until it has no longer customers or its production cost is not justified. Therefore, its corrective, preventive, and inspection maintenance should be changed into condition based, reliability based and risk based maintenance respectively.

Thus, the experience in operation and maintenance is needed to be utilized in order to extend its operational life.[9] The weak points of the equipment can be identified from its historical corrective maintenance records. Some equipment's running conditions should be timely monitored. Moreover, the preventive maintenance schedule should more focus on its unreliable parts.[10] The periodic inspection maintenance should concentrate on some major parts. The deterioration mechanism of the major parts should be followed up properly.

From an asset management's historical perspective, the learning processes of a factory on the operation and maintenance are develop through the operation and maintenance activities.[11] The learning model is based on experience collectively gained over a period of time. Anyhow, it is a time consuming process with many staffs involved to develop best practices. Hence, it requires a step-by-step development from breakdown to proactive maintenance.[12] In the breakdown 
maintenance scheme, equipment is disassembled and assembled to get the basic knowledge in plant installation and commissioning. Corrective maintenance scheme represents knowledge on diagnosis when failures occur. In preventive maintenance scheme, most activities involve resource scheduling to avoid unplanned outages. Predictive maintenance scheme indicates the abilities of the knowledge workers to foresee the future faults and events based on the present condition of equipment.[13] Finally, with more knowledge gained over an operating period, the proactive maintenance indicates abilities of the knowledge workers to assess the asset lifetime as well as its' parts that consequently assists the utilities in the decision making on the replacement or the refurbishment. Furthermore, the associated costs and risks can be reduced from the experience of maintenance while more knowledge has increasingly been gained over a period of time.

\section{Methodology}

A Korean FDI relocated electronic factory in Thailand has been selected as a case study. The asset management is introduced to improve the factory preventive maintenance scheme. The asset management procedure includes three stages; 1) Asset Survey 2) Knowledge Management applied in Asset Study and 3) Maintenance mode selection. See Fig. 1.

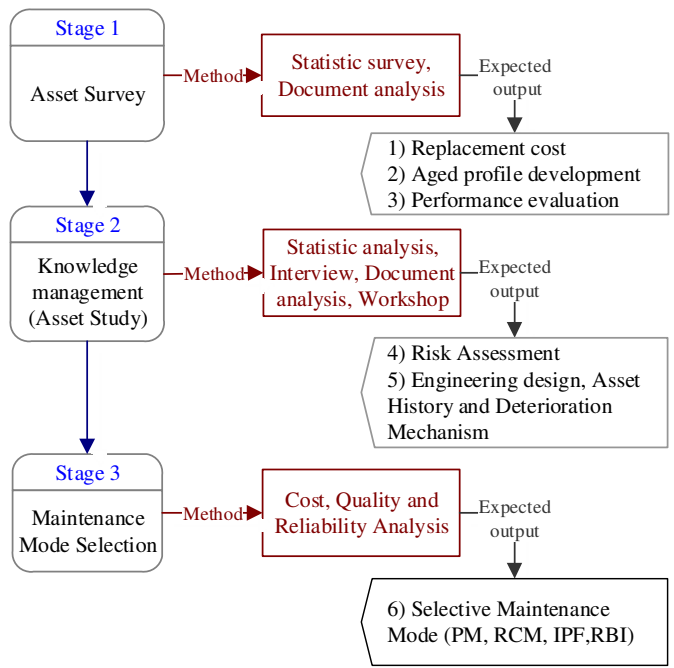

Fig. 1. Stages of the methodology 
Firstly the asset survey shall be conducted. Each asset in the factory needs to be evaluated for its replacement cost. Normally the replacement cost can be received from its manufacturer for brand new equipment. But in some cases, equipment has already been no longer manufactured. Then the replacement cost can be assumed as the price when it was initially purchased. The prioritization should be done from the most expensive replacement cost to the least one. Top three expensive assets should be in a short list under consideration. Later, the aged profile curve should be plotted for high priority equipment. Normally, an individual machine that is beyond 20 years should be focused. The further focus should be given to the too old ones. Then performance including availability and reliability of the old assets should be evaluated.

Secondly, Knowledge Management shall be applied in Asset Study. The risk assessment should be done on the targeted assets by using risk assessment matrix, and the knowledge acquisition should be done on its design versus operation, maintenance history and deterioration mechanism.

Finally, based on the acquired knowledge, the suitable maintenance method such as Risk Based Inspection, Reliability Centered Maintenance or Instrumental Protective Function for particular equipment is then selected to improve the traditional preventive maintenance procedure.

\section{$4 \quad$ Analysis and Results}

\subsection{Replacement cost}

In evaluating the replacement cost, it is required to classify the overall asset. This asset is classified into 3 categories which are;

- Class A, the main machinery which directly affect to the production capability

- Class B, the supporting machinery to the main machinery

- Class C, instrument which does not need maintenance service

In this study, only machinery in class A shall be identified the replacement cost.

The replacement cost is evaluated at the new purchasing price of machinery from the existing manufacturers. The example of replacement cost of Bonding and Molding machinery that their life are over than 5 years, are evaluated as following Fig. 2 and Fig. 3. 


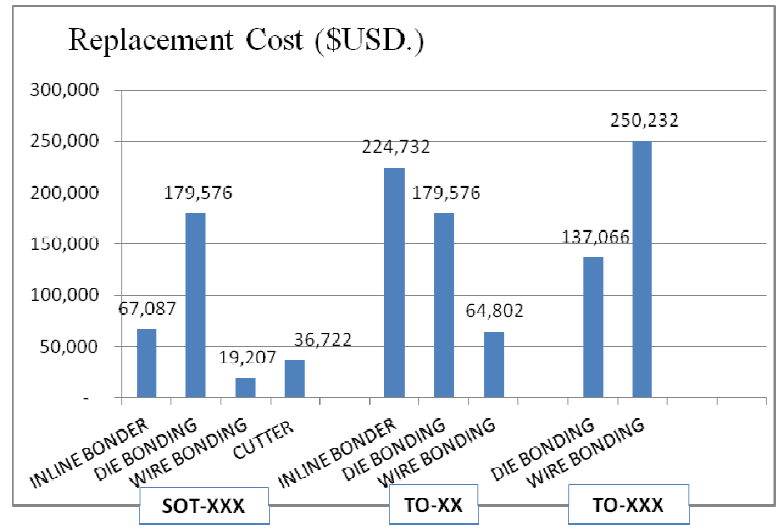

Fig. 2. Replacement Cost of Bonding Machinery by Product

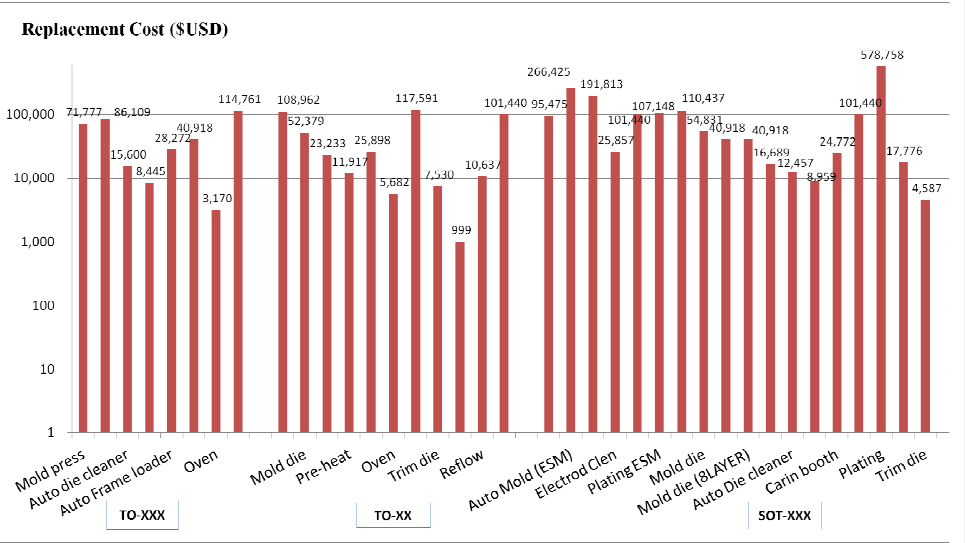

Fig. 3. Replacement Cost of Molding Machinery by Product

\subsection{Aged profile development}

Aged profile shows the investment in replacing machinery according to their ages. The life extension of these machineries is considered and expected to provide at least 15 years extension. The aged profile of three main machineries is shown in Fig. 4, 5 and 6. 


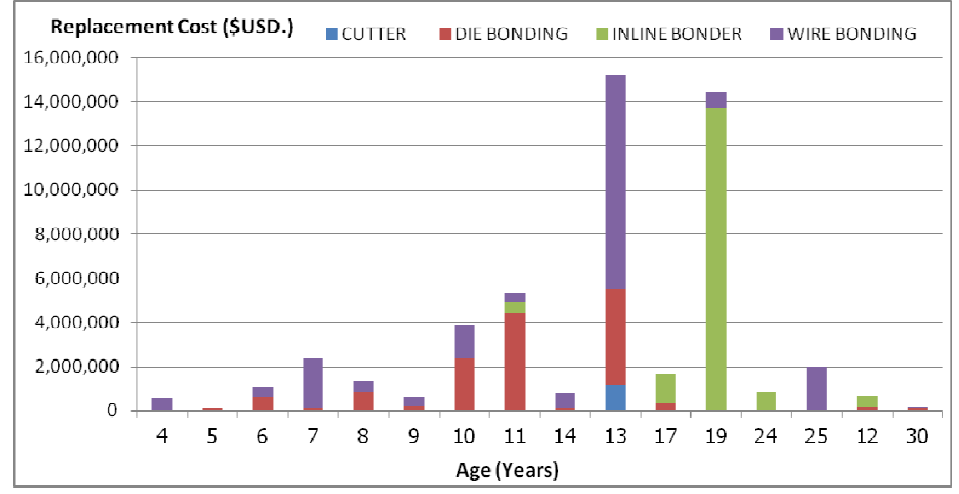

Fig. 4. Aged Profile by the Replacement Cost of Bonding Machinery Group

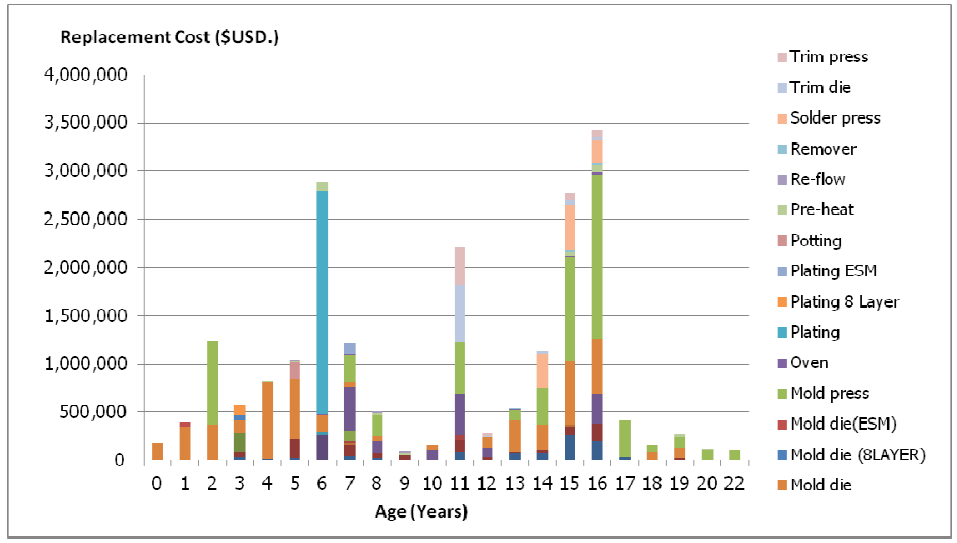

Fig. 5. Aged Profile by the Replacement Cost of Molding Machinery Group 


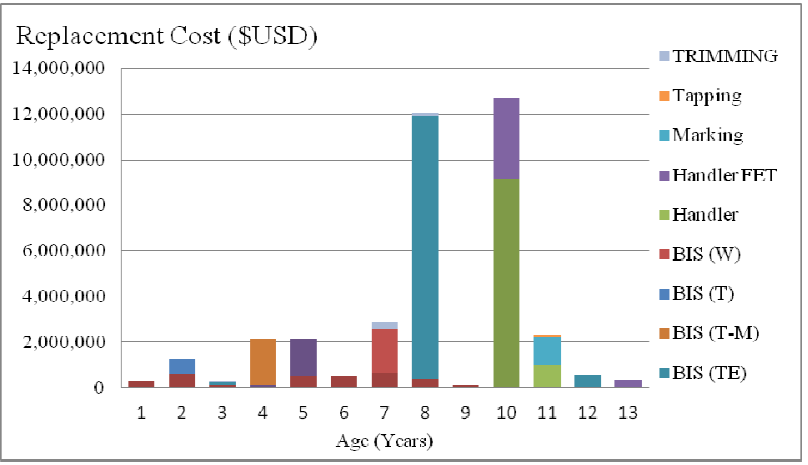

Fig. 6. Aged Profile by the Replacement Cost of BIS Machinery Group

According to the age categories in this study, there are 4 recovery operations for 4 age levels, aiming at recapturing value from its End of Life as follows,

- Recycling the breakdown and low performance machine which its life is more than

20 years. The purpose is to reuse parts by various separation processes and reusing them in the other machine.

- Repairing and reusing the breakdown machine but still in a good performance which its life is from 10 years in order to return it service in working order by changing parts.

- Reviewing the maintenance plan of the machine that its life is from 5 years by increasing PM or applying Reliability Centered Maintenance (RCM), Risk Based Inspection and Monitoring only the Instrumental Protective Function in order to protect the low service performance.

- Relying on the manufacturing manual to maintain the operation function of machine which its life is less than 5 years

\subsection{Performance evaluation}

The factors to evaluate the Service Performance of the machinery include 12 variables (See Table 1.). From the normalization graph of variable number 5 to 12, it is found that SOT-XXX production line possesses the overall highest performance among three production lines (See Fig. 7.). It is suggested that the production line of TO-XX and TO-XXX product should decrease the Preventive Maintenance. Some machines should be recycled or refurbished. The running capacity of these two production lines is still lower than the acceptable ratio, so there is an opportunity to build a stock of regularly ordered product. 
Table 1. Service performance evaluation

\begin{tabular}{|c|c|c|c|c|c|c|c|}
\hline $\mathbb{N}_{\mathbf{c}}$ & \multirow[b]{2}{*}{ Statement } & \multicolumn{2}{|c|}{ SOT-XOXX } & \multicolumn{2}{|c|}{ TO-EXX } & \multicolumn{2}{|c|}{ TO-XXX } \\
\hline 140 & & Actual & Acceptable & Actual & Acceptable & Actual & Acceptable \\
\hline 1 & Quality of Service (Class A, B, C) & $\mathrm{A}$ & & $\mathrm{B}$ & & c & \\
\hline 2 & Number of Customer (total $=A+B+C)$ & 4 & & 6 & & 5 & \\
\hline 3 & Production Order (no./yr) & 4,800 & 4,872 & 558 & 569 & 330 & 335 \\
\hline 4 & Revenue (\$USD/yr) & $33,600,000$ & & $4,482,000$ & & $4,950,000$ & \\
\hline 5 & Gross Profit (\%) & $9 \%$ & $6 \%$ & $-10 \%$ & $6 \%$ & $-10 \%$ & $6 \%$ \\
\hline 6 & Scrab (\%/yr) & $3 \%$ & $2.5 \%$ & $2.50 \%$ & $2 \%$ & $2 \%$ & $1.5 \%$ \\
\hline 7 & Running Capacity & $100 \%$ & $80 \%$ & $50 \%$ & $80 \%$ & $66 \%$ & $80 \%$ \\
\hline 8 & Claim (no./year (Defect)) & 3 & 5 & 40 & 6 & 4 & 1 \\
\hline 9 & Outage (day/year) & 12 & 16 & 35 & 120 & 50 & 24 \\
\hline 11 & Total Down Time (Minor+Breakdown) & $11 \%$ & $5 \%$ & $12 \%$ & $5 \%$ & $2 \%$ & $5 \%$ \\
\hline 12 & Bonding Down Time (Minor+Breakdown) & $11 \%$ & $5 \%$ & $12 \%$ & $5 \%$ & $2 \%$ & $5 \%$ \\
\hline
\end{tabular}

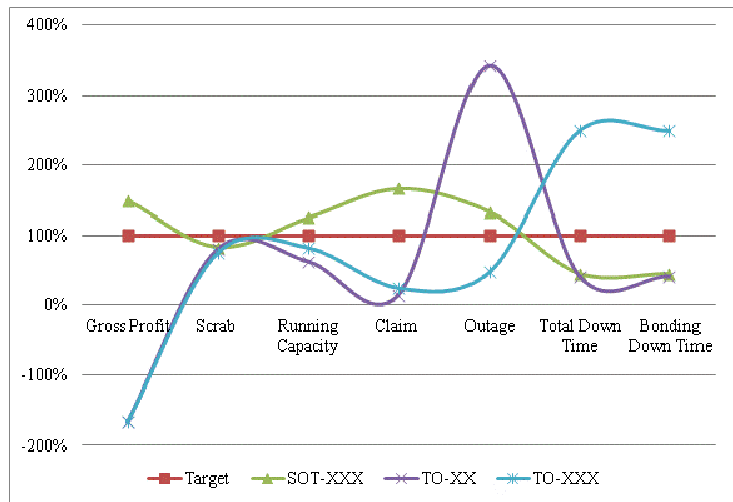

Fig. 7. Service Performance of 7 variables

\subsection{Risk Assessment}

Risk Assessment Matrix is used to assess the risk of each machine. It requires the participation of knowledge workers and the experienced technicians. This is needed to assess the possibility to be breakdown and the seriousness of problem and assess risk into three levels (High - Medium - Low) together with its part's lifetime while providing the subsequent action needed of each part. (see Fig. 8) 


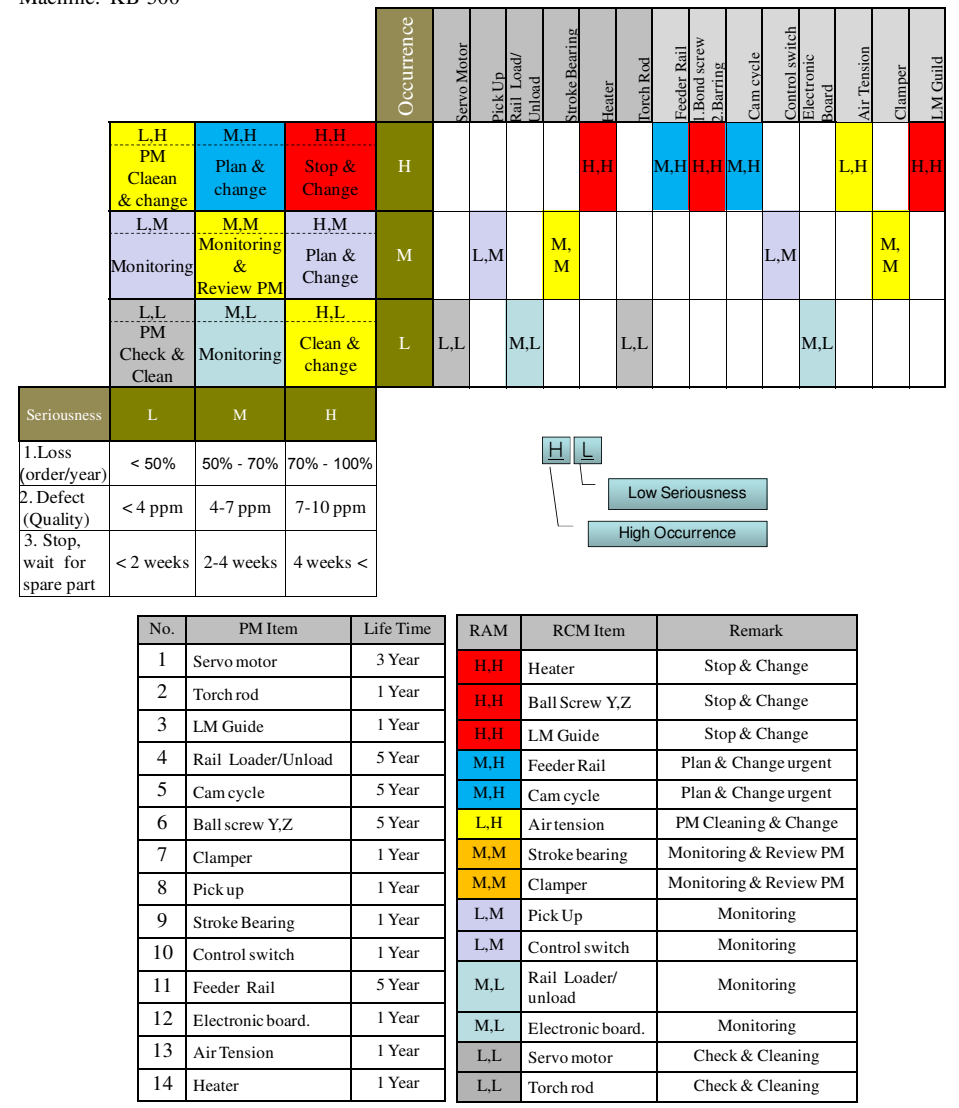

Fig. 8. Risk Assessment Matrix

\section{Asset Study: Engineering design, History and Deterioration Mechanism}

After assessment and collecting the lifetime of each part of the machine by the risk assessment matrix, the experienced technicians shall examine the machinery 
engineering design, its operation, maintenance history and parts deterioration mechanism in order to understand and plan its maintenance mode. See the sample of the asset study of the Back Inline System (BIS) machine in Fig. 9.

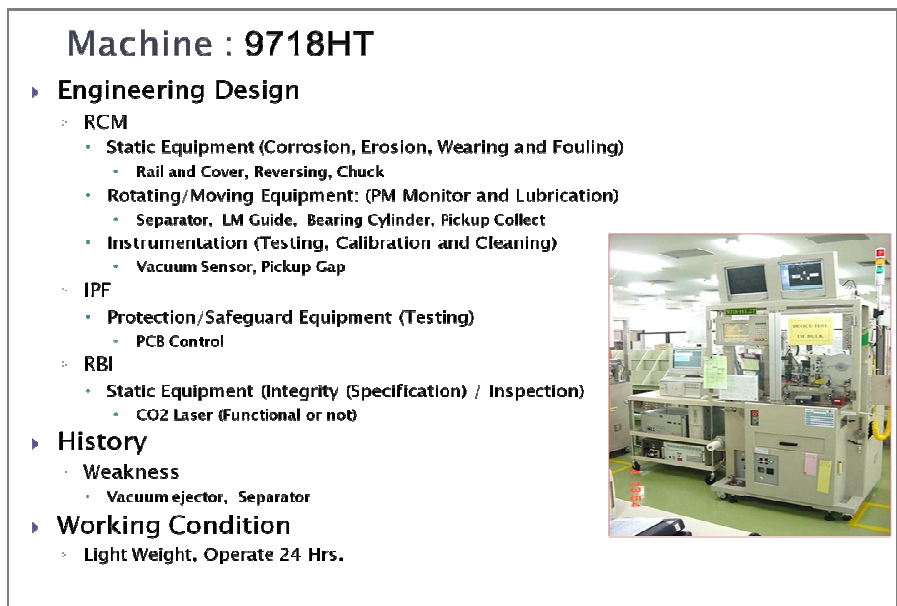

Fig. 9. Engineering design, operation and maintenance history study

The machine part is classified into 5 categories; Static equipment, Rotating/Moving Equipment, Instrumentation, Instrumental Protective Function (IPF) and Static Equipment which identifies its lifetime. The Deterioration Mechanism study of each part in 5 categories is shown in Fig. 10.

After studying the asset, which is based on the acquired knowledge of machinery engineering design, its operation, maintenance history and parts deterioration mechanism; the maintenance mode shall be suitable and selective according to its design and deterioration mechanism. There are three selective maintenance modes, Risk Based Inspection (RBI), Reliability Centered Maintenance (RCM) and Instrumental Protective Function (IPF), proposed for individual equipment, which is described in Table 2 . 
1. Static Equipment: No movement but has a risk in Corrosion, Erosion, Wearing and Fouling

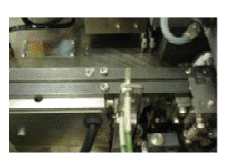

Rall \&cover

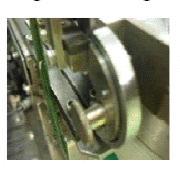

Reversing

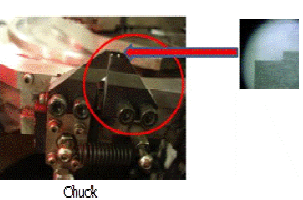

2. Rotating/Moving Equipment: Need PM Monitor and Lubrication

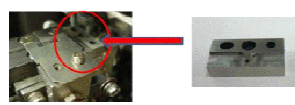

sabalator
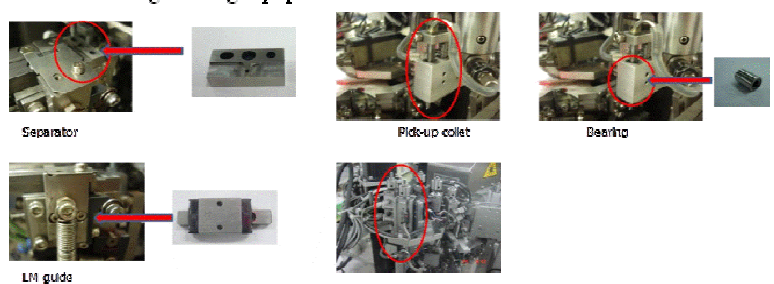

Cyinder

3. Instrumentation: Need Teiting, Calibration and Cleaning
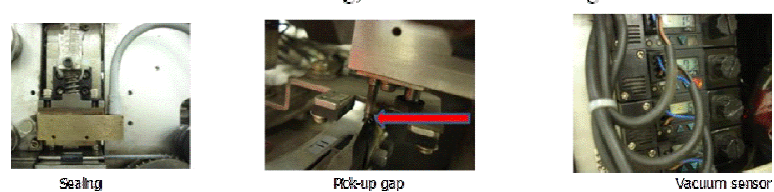

4. Tnstrum ental Protective Function (Protection/Safegnard Equipment snch as electromic control system) : Need Testing

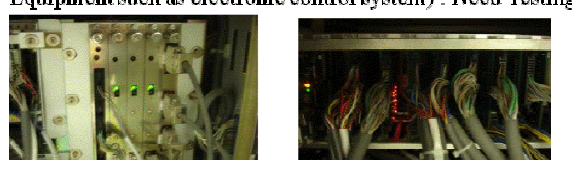

5. Static Espripment which prescribed its lifetime: Need Integrity (Specification) and working condition Inspection
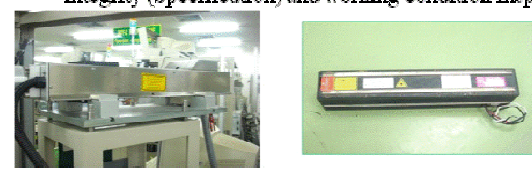

Fig. 10. Machine part's Deterioration Mechanism 
Table 2. Maintenance mode selection

\begin{tabular}{|l|l|c|l|}
\hline \multicolumn{2}{|c|}{ Type of Equipment } & $\begin{array}{c}\text { Maintenance } \\
\text { Mode }\end{array}$ & \multicolumn{1}{|c|}{ How to Maintain } \\
\hline 1 & Static Equipment & \multirow{2}{*}{ RCM } & $\begin{array}{l}\text { Monitoring its corrosion, } \\
\text { erosion, wearing and } \\
\text { fouling condition }\end{array}$ \\
\cline { 1 - 2 } 2 & $\begin{array}{l}\text { Rotating/Moving Equipment } \\
\text { Previtoring,doing } \\
\text { Prentive Maintenance } \\
\text { and Lubricating }\end{array}$ \\
3 & Instrumentation & $\begin{array}{l}\text { Testing, Calibrating and } \\
\text { Cleaning }\end{array}$ \\
\hline 4 & $\begin{array}{l}\text { Instrumental Protective } \\
\text { Function (Safeguard } \\
\text { Equipment) }\end{array}$ & IPF & Testing its operation \\
\hline 5 & $\begin{array}{l}\text { Static Equipment which } \\
\text { prescribed its lifetime }\end{array}$ & RBI & $\begin{array}{l}\text { Checking Integrity } \\
\text { Specification) and } \\
\text { Inspection its function }\end{array}$ \\
\hline
\end{tabular}

\section{Discussion}

\subsection{Integration of new maintenance mode to existing maintenance system}

Through the process of asset survey and study, a new maintenance mode is introduced but it should be applied with the existing maintenance system in the firm. This Korean FDI already has its own maintenance system, but it focuses on the Preventive maintenance, which may lead to the excessive maintenance cost. Therefore, the RCM, RBI and IPF maintenance mode shall reduce the over-maintenance cost. The new maintenance mode integrating with the existing maintenance system can be illustrated in Fig. 11.

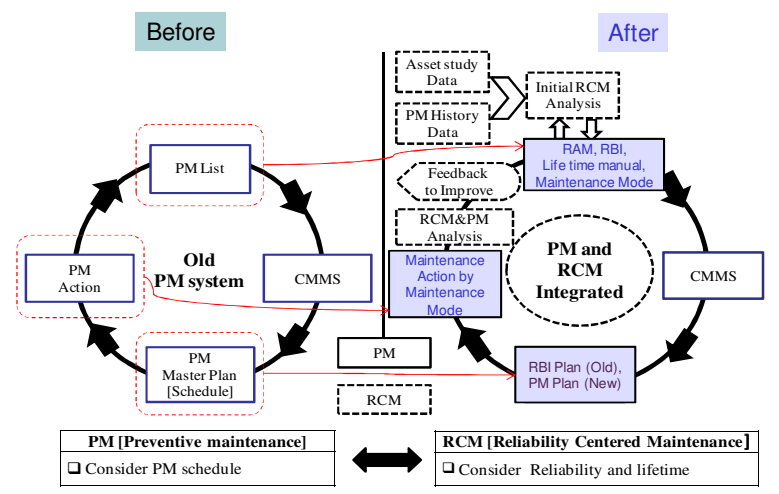

Fig. 11. Reliability Centered Maintenance integrating with existing maintenance system 
The old PM system provided a PM master plan based on machine manufacturer recommendation. The technician took an action on daily monitoring, cleaning, lubricating and changing parts and report in the PM, then, input the report in CMMS. After RCM integrating, the technicians study machine deterioration mechanism and PM history, then, make Risk Assessment (RAM) and RBI (Risk Based inspection) based on their experience. The technicians use RAM data to build a maintenance Mode instruction and, together with their experience, make a Machine Life Time Justification manual. After input to CMMS, then, the RBI plan for old machine and PM plan for new machinery, which is not over 5 years old, are scheduled. Later technician maintain the machine according to the prior designed maintenance mode. Finally, the problem in the maintenance work is discussed and feedback to the maintenance team for improvement.

\subsection{Reliability and Quality Improvement}

There is an indicator showing that after applying the new selective maintenance mode, in the middle of 2011 , the process reliability is improved. Considering the record of Outgoing Quality Control (OQC) of all products after the production line applied the new maintenance mode. The number of OQC reject caused by machine failure at the end of 2012 was significantly reduced $81 \%$ from the first half 2011 , See Table 3.

Table 3. OQC rejected by machine failure in 2011-2012

\begin{tabular}{|c|r|r|r|r|}
\hline OQC Reject Caused & \multicolumn{2}{|c|}{2011} & \multicolumn{2}{c|}{2012} \\
\cline { 2 - 5 } By Machinery & 1st Half & 2nd Half & 1st Half & 2nd Half \\
\hline Target (Time) & 42 & 42 & 24 & 24 \\
\hline Actual (Time) & 47 & 25 & 14 & 4 \\
\hline$\%$ to target & $112 \%$ & $60 \%$ & $58 \%$ & $17 \%$ \\
\hline$\%$ to Last Period & $100 \%$ & $53 \%$ & $30 \%$ & $9 \%$ \\
\hline
\end{tabular}

\subsection{Maintenance Cost Improvement}

There is also a record of maintenance expense that shows a big improvement in maintenance cost before and after the application of new maintenance mode. (See Table 4.) Initially, they generate the Preventive Maintenance cost plan at the beginning of the fiscal year. The first half of 2011, before the application of new selective maintenance mode, they spent $94 \%$ of the annual budget. But after the application of new maintenance mode, the cost of maintenance was reduced to $37 \%$ of the budget. 
Table 4. Maintenance Cost in 2011-2012

\begin{tabular}{|c|c|c|c|c|}
\hline \multirow{2}{*}{ Malnten ane $\bullet$ Cost by Yoar (K\$USD) } & \multicolumn{2}{|c|}{$2 \mathrm{J11}$} & \multicolumn{2}{|c|}{$2 J 12$} \\
\hline & 15tHalf & 2nd Half & 1st Half & 2nd Half \\
\hline PH FostB Jdyet Plan & 685 & $\angle 30$ & 684 & 716 \\
\hline Act.al $\operatorname{Cos}$ & 647 & 351 & 435 & $26^{7}$ \\
\hline$\%$ of Usage & $94 \%$ & $82 \%$ & $64 \%$ & $37 \%$ \\
\hline Save Cost & 38 & 79 & 249 & 449 \\
\hline 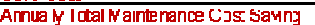 & & 111 & & Вषप् \\
\hline
\end{tabular}

\subsection{Emerging of Knowledge Retention}

Prior to the research's commencing, most of the experienced technicians with current average 13 years working as senior technicians never externalize their tacit knowledge in any kind of media. Many of them left the firm without knowledge retention. But through the process of asset study, they had used their experience to justify the machine risk with the risk assessment matrix, as well as the risk based inspection and part life time. Their knowledge was elicited and documented online to share to the technician community. The knowledge was delivered to other maintenance members in the form of books (a Machine Part Lifetime Justification book and a Machine Risk Inspection book). The knowledge is also retained within the organization. . The knowledge retention, then, was activated and delivered to the less experienced junior technicians. The process of knowledge capturing and retention is illustrated in Fig. 12.

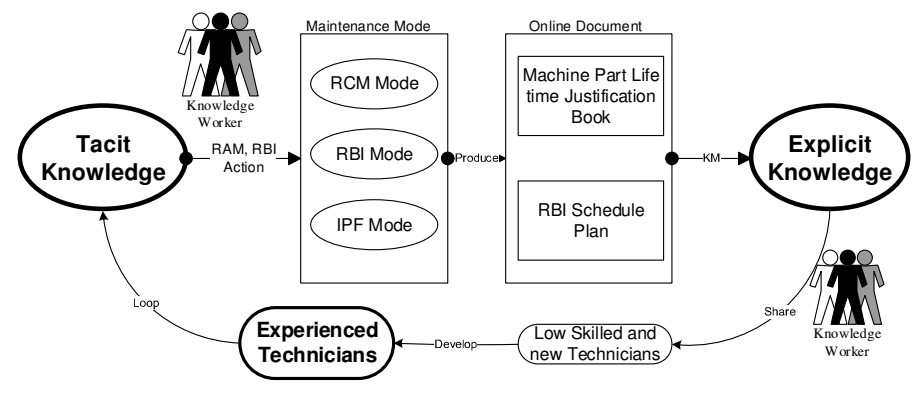

Fig. 12. Process of knowledge capturing and retention

\subsection{Intellectual capital growth}

After implementing the RCM as the knowledge based maintenance, the actual financial and intellectual capital performances of relocated machinery had been observing for 2 years from 2012 to 2013 . It can be seen that both performances were significantly increased. The researchers had further made a calculation model and forecasted the 5-year performance from 2014 to 2018. The result shows significant ratios that the relocated machinery possesses a competitive advantage in intellectual 
capital. During 7 years from 2012 to 2018, Human Capital is 9 times of Human Asset. Total market capital is \$431 Million USD, with the intellectual capital 59\% (\$254 Million USD) and financial capital is $41 \%$ (\$ 177 Million USD) as exhibited in fig. 13

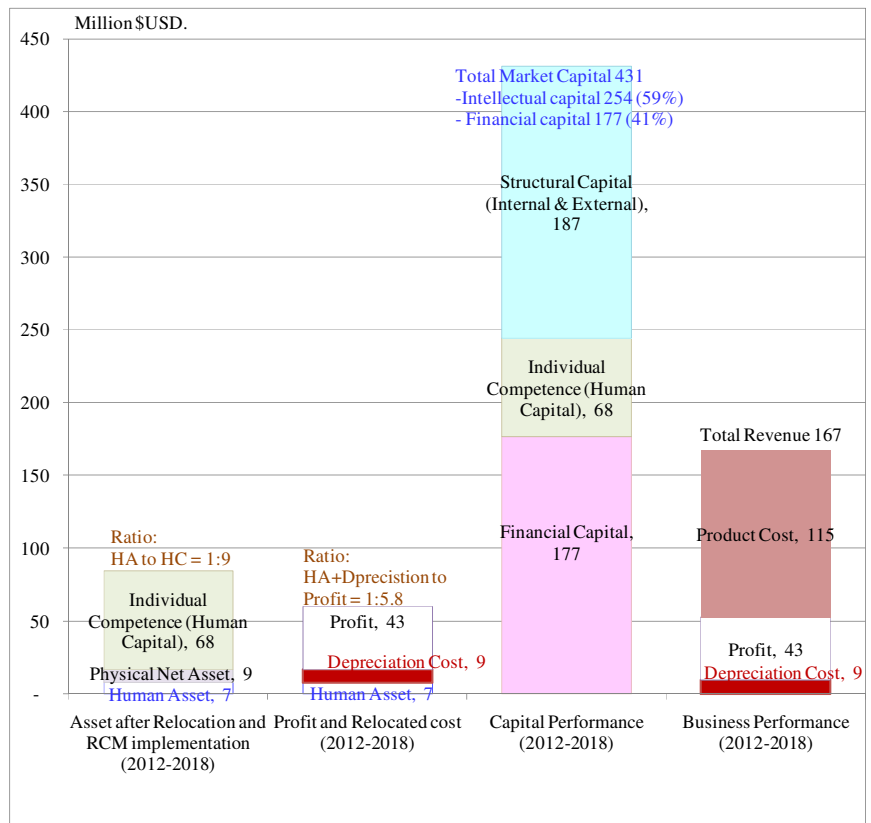

Fig. 13. Tangible and intangible performance

\section{Conclusion}

Since the core manufacturing factors are people, process and product, therefore the management of the end-of-life product manufacturing also requires the improvement of those three factors. A new financial strategy of the obsolete product should be applied to stretch its intellectual capital. The asset management plan should be applied to improve the manufacturing process. And the knowledge management should be applied to improve the knowledge of manufacturing technical people. These can make extra corporate value including stock market value and customer satisfaction. Therefore, the problem of product and process end of life can be solved by the shift of maintenance system with knowledge management. The case study in this paper also showed the explicit improvement of reliability, quality and product cost. Moreover, it also retains the knowledge of the experienced technicians before their retirement or 
resignation. The whole process of Asset management could help the firms to endure their product life cycle.

\section{Reference}

1. D. W. t. Velde, "Foreign Direct Investment and Development-An historical perspective," Background paper for "World Economic and Social Survey for 2006', p. 5 (30 January 2006)

2. B. R. Mishra, "Inward FDI and firm-specific advantages of Indian manufacturing industries," MPRA Paper No. 35119, Munich University Library, Germany (2011)

3. R. E. Lipsey, "Home- and Host-Country Effects of Foreign Direct," Challenges to Globalization: Analyzing the Economics, pp. 335-336 (February 2004)

4. S. Urata and H. Kawai, "Intrafirm Technology Transfer by Japanese Manufacturing Firms in Asia," The Role of Foreign Direct Investment in East Asian Economic Development, NBER-EASE Volume 9, p. 51 (January 2000)

5. J. K. Kim, "Korea Economic Relations with Southeast Asia," in Korea's Changing Roles in Southeast Asia: Expanding Influence and Relations, D. I. Steinberg, Ed., Singapore, ASEAN-Korea Centre, Institute of Southeast Asian Studies, p. 90 (2010)

6. R. Enparantza, O. Revilla, A. Azkarate and J. Zendoia, "A Life Cycle Cost Calculation and Management System for Machine Tools," in 13th CIRP international conference on life cycle engineering, Belgium (2006)

7. A. Sundberg, "Management aspects on Condition Based Maintenance-the new opportunity for maritime industry," in The 9TH International Conference on Marine Engineering Systems, Helsinki University of Technology, Finland (2003)

8. UNCTAD World Investment Report 2013, UNITED NATIONS CONFERENCE ON TRADE AND DEVELOPMENT, pp. 159-160 (2013)

9. J. Moubry, "Maintenance Management- A New Paradigm," in Maintenance, pp. 10-11 (1996)

10. L. Bertling, R. Allan and R. Eriksson, "A Reliability-Centered Asset Maintenance Method for Assessing the Impact of Maintenance in Power Distribution Systems," IEEE TRANSACTIONS ON POWER SYSTEMS, vol. 20, no. 1, p. 81 (February 2005)

11. D. Sherwin, "A review of overall models for maintenance management," Journal of Quality in Maintenance Engineering, vol. 6, no. 3, pp. 138-164 (2000)

12. S. Legutko, "Modern approach to machines operation maintenance," Manufacturing Engineering/ Vyrobne Inzinierstvo, vol. 6, no. 4, pp. 91-95 (2007)

13. I. Ahuja and J. Khamba, "Total Productive Maintenance: Literature Review and Directions," International Journal of Quality \& Reliability Management, vol. 25, no. 7 , pp. $712-714(2008)$ 